\title{
Neglect of lactation stage leads to naive assessment of residual feed intake in dairy cattle
}

\author{
B. Li, ${ }^{*}{ }^{1}$ B. Berglund, ${ }^{*}$ W. F. Fikse, ${ }^{*}$ J. Lassen,, M. H. Lidauer, $\ddagger$ P. Mäntysaari, $\ddagger$ and P. Løvendahl† \\ *Department of Animal Breeding and Genetics, Swedish University of Agricultural Sciences, SE-750 07 Uppsala, Sweden \\ †Department of Molecular Biology and Genetics, Aarhus University, DK-8830 Tjele, Denmark \\ ‡Natural Resources Institute Finland, Green Technology, FI-31600 Jokioinen, Finland
}

\section{ABSTRACT}

Residual feed intake (RFI) is a candidate trait for feed efficiency in dairy cattle. We investigated the influence of lactation stage on the effect of energy sinks in defining RFI and the genetic parameters for RFI across lactation stages for primiparous dairy cattle. Our analysis included 747 primiparous Holstein cows, each with recordings on dry matter intake (DMI), milk yield, milk composition, and body weight (BW) over 44 lactation weeks. For each individual cow, energy-corrected milk (ECM), metabolic BW (MBW), and change in BW $(\Delta \mathrm{BW})$ were calculated in each week of lactation and were taken as energy sinks when defining RFI. Two RFI models were considered in the analyses; RFI model [1] was a 1-step RFI model with constant partial regression coefficients of DMI on energy sinks (ECM, MBW, and $\triangle \mathrm{BW}$ ) over lactation. In RFI model [2], data from 44 lactation weeks were divided into 11 consecutive lactation periods of $4 \mathrm{wk}$ in length. The RFI model [2] was identical to model [1] except that period-specific partial regressions of DMI on ECM, MBW, and $\triangle \mathrm{BW}$ in each lactation period were allowed across lactation. We estimated genetic parameters for RFI across lactation by both models using a random regression method. Using RFI model [2], we estimated the period-specific effects of ECM, MBW, and $\triangle \mathrm{BW}$ on DMI in all lactation periods. Based on results from RFI model [2], the partial regression coefficients of DMI on ECM, MBW, and $\triangle \mathrm{BW}$ differed across lactation in RFI. Constant partial regression coefficients of DMI on energy sinks over lactation was not always sufficient to account for the effects across lactation and tended to give roughly average information from all period-specific effects. Heritability for RFI over 44 lactation weeks ranged from 0.10 to 0.29 in model [1] and from 0.10 to 0.23 in

Received February 21, 2017.

Accepted July 24, 2017.

${ }^{1}$ Corresponding author: bingjie.li@slu.se model [2]. Genetic variance and heritability estimates for RFI from model [2] tended to be slightly lower and more stable across lactation than those from model [1]. In both models, RFI was genetically different over lactation, especially between early and later lactation stages. Genetic correlation estimates for RFI between early and later lactation tended to be higher when using model [2] compared with model [1]. In conclusion, partial regression coefficients of DMI on energy sinks differed across lactation when modeling RFI. Neglect of lactation stage when defining RFI could affect the assessment of RFI and the estimation of genetic parameters for RFI across lactation.

Key words: residual feed intake, dairy cattle, energy sink, lactation stage, genetic parameter

\section{INTRODUCTION}

Alternative feed efficiency (FE) traits have been explored recently to select for efficient animals that better use feed energy for production without sacrificing animal health or fertility in the long run. Residual feed intake (RFI), as one proposed FE trait, has been widely studied in pig, chicken, beef cattle, and dairy cattle (Berry and Crowley, 2013; Wolc et al., 2013; Patience et al., 2015; Tempelman et al., 2015). Generally, RFI is defined as the difference between an animal's actual feed intake and its expected feed intake based on energy requirements for body maintenance and production (Koch et al., 1963). Individuals with lower RFI are considered to be more efficient. In dairy cattle, milk production, body maintenance, and BW change $(\Delta \mathbf{B W})$ are usually included as key energy sinks when defining RFI. The expected feed intake of cows is derived from partial regressions of the feed intake on energy sinks (VandeHaar et al., 2016).

Defining RFI in lactating dairy cows is more complicated than defining RFI in growing animals due to the metabolic changes that occur during lactation cycles (Berry and Crowley, 2013). In early lactation, the milk production of dairy cows increases more sharply than feed intake, and body reserves need to be mobilized to 
meet the energy demand (Berglund and Danell, 1987; Roche et al., 2009; Banos and Coffey, 2010). In later lactation, the feed intake of cows is kept at a relatively high level and body reserves are gradually restored (Mao et al., 2004; Vallimont et al., 2010). Generally, the commonly used RFI model employs constant partial regressions of feed intake on energy sinks. Considering the complexity of the metabolic changes of cows across lactation, it is possible that the partial regression coefficients of feed intake on milk production, body maintenance, and $\triangle \mathrm{BW}$ could vary across lactation. Therefore, the general RFI model with constant partial regression coefficients of feed intake on energy sinks might not always hold for the entire lactation period, which might influence the estimation of RFI. Most previous studies corrected for the influence of lactation stages on RFI by using a systematic effect of DIM or lactation week on feed intake, or by including random regression terms in the model for the influence of lactation stage on cow random variances (Mäntysaari et al., 2012; Hardie et al., 2015; Tempelman et al., 2015). However, these commonly used corrections of lactation stages on RFI have ignored the potential influence of lactation stage on the partial regression coefficients of feed intake on energy sinks, and very few studies have been carried out to explore this potential influence when defining RFI. Lu et al. (2017) investigated the influence of management and environmental factors on partial efficiency of converting feed intake to energy sinks for RFI using a Bayesian multivariate modeling method, where the linear and quadratic effects of DIM on the partial efficiency of feed intake on energy sinks tended to be insignificant when 42 - $\mathrm{d}$ records between 50 and 200 DIM were studied.

Previous studies reported heritability estimates for RFI in dairy cattle that ranged widely from 0.00 to 0.38 (Berry and Crowley, 2013; Tempelman et al., 2015; Manzanilla-Pech et al., 2016) and tended to vary across lactation (Tempelman et al., 2015). In dairy cattle, the genetic correlation for RFI across lactation has rarely been reported. A recent study showed a low genetic correlation for residual energy intake between early lactation and lactation wk 20 in Nordic Red cows (Liinamo et al., 2015).

The objectives of the current study were to investigate the influence of lactation stage on the partial regression coefficients of feed intake on energy sinks when modeling RFI, and also to estimate the genetic parameters for RFI across lactation in dairy cattle. Two RFI models were studied in which partial regression coefficients of feed intake on energy sinks were allowed or not allowed to change across lactation. Genetic parameters for RFI were estimated across lactation and were compared between the 2 RFI models.

\section{MATERIALS AND METHODS}

\section{Animals, Feeding, and Data Recording}

Cows in our study were from the Danish Cattle Research Center (DCRC; Foulum, Denmark) and the Ammitsbøl Skovgaard research herd (Skovgaard, Vejle, Denmark). From the raw data set containing records for 1,749 lactations of 890 Holstein cows, our study included data from 823 primiparous Holstein cows that calved between 1995 and 2015. Cows had been involved in some experiments on the farm (Nielsen et al., 2003; Løvendahl et al., 2010; Løvendahl and Chagunda, 2011). Studied Holstein cows included all Holstein cows from the DCRC studied by Li et al. (2016).

Cows were fed a TMR in weigh bins at DCRC (RIC System, Insentec B.V., Marknesse, the Netherlands). A planned quantity of concentrates was dispensed during each milking in the automatic milking system and leftover quantity was recorded. At Skovgaard, cows were kept and fed in tiestalls, with TMR dispensed manually. Components in the TMR were mainly maize, whole-crop, and grass silage supplied with sugar-beet expellers and protein concentrates. The energy content of feed could be slightly different between trials but was generally constant within each trial. The TMR and concentrates offered to cows and the feed refusals were measured individually to calculate the individual feed intake per cow. The DM contents of the TMR and concentrates were analyzed regularly, and the compositions were aligned and merged with feed intake records to obtain daily DMI per cow. A weekly average DMI per cow was calculated as the average of 7 DMI daily records in each lactation week. Energy intake per cow was not available.

Cows were milked twice daily at Skovgaard and had voluntary access to automatic milking systems at DCRC. The approach of ICAR (2016) was used with a moving average over $3 \mathrm{~d}$ to obtain daily milk yield (MY), where the daily MY was obtained from the average milking rate (calculated from the sum of the yield over $3 \mathrm{~d}$ divided by the sum of milking intervals in the same period) multiplied by $24 \mathrm{~h}$. Milk composition was measured in all samples from every milking taken over a consecutive 48-h period every week. Milk composition was analyzed by using CombiFoss equipment (Foss, Hillerød, Denmark) operated by Eurofins (Vejen, Denmark). Composition data from each milking were used to calculate yields of fat, protein, and lactose, which were smoothed by the moving average method to obtain daily yields. Calculated daily yields were averaged per week of lactation to get the weekly average yields, similar to the DMI records. At Skovgaard, BW per cow was recorded every week during lactation wk 
1 to 12 , and every other week during wk 13 to 44 . At DCRC, cows were weighted at every milking, and the BW records per cow were averaged per week of lactation to get the weekly BW.

\section{Data Editing}

The data set for our study included weekly records of DMI, MY, milk composition (fat, protein, lactose contents), and $\mathrm{BW}$ of the primiparous Holstein cows within the 44 lactation weeks. Cows that were older than 36 mo at first calving and cows with fewer than 5 weekly records of DMI, MY, milk composition, or BW over the 44 lactation weeks were removed from the data set. After data editing, the final data set for the statistical analysis consisted of 747 primiparous Holstein cows with 24,993 weekly records on DMI, MY, milk composition, and BW. Age range at first calving was 24 to 36 mo. Each cow had an average of 33 weekly records (Table 1). Pedigree information was extracted from the Nordic Cattle Genetic Evaluation Database (Skejby, Denmark) by tracing back as many generations as possible for cows with records.

\section{Statistical Analysis}

Energy-corrected milk, metabolic BW (MBW), and $\triangle \mathrm{BW}$ were calculated individually in each lactation week. The ECM $(\mathrm{kg})$ was obtained from MY $(\mathrm{kg})$ and milk composition $(\mathrm{g} / \mathrm{kg})$ by using $\mathrm{ECM}=\mathrm{MY} \times$ $[(38.30 \times$ fat content $+24.20 \times$ protein content +16.54 $\times$ lactose content +20.7$) / 3,140]$ (Sjaunja et al., 1990). The weekly BW per cow over 44 lactation weeks was modeled by a third-order Legendre polynomial function of lactation weeks. And the $\Delta \mathrm{BW}$ per cow at each lactation week was obtained from the first derivative (i.e., the slope) of the fitted BW curve of each cow; MBW was computed as BW $\mathrm{BW}^{0.75}$ (McDonald et al., 2011).

Two RFI models were considered. Model [1] is a 1-step RFI model that combines the energy sink model for estimating RFI and the genetic model ( $\mathrm{Lu}$ et al., 2015; Tempelman et al., 2015). In model [1], the partial regression coefficient of DMI on each energy sink (ECM, MBW, and $\triangle \mathrm{BW}$ ) was considered to be constant over lactation. Residual feed intake model [2] considered period-specific partial regressions of DMI on $\mathrm{ECM}, \mathrm{MBW}$, and $\triangle \mathrm{BW}$ for each lactation period, with the whole lactation (44 lactation weeks) being divided into 11 consecutive 4 -wk lactation periods. The 2 models were identical except for the period-specific partial regressions of DMI on energy sinks in the latter model:

$$
\begin{aligned}
\mathrm{DMI}_{\mathrm{jklmp}}= & \mathrm{b}_{1} \mathrm{ECM}+\mathrm{b}_{2} \mathrm{MBW}+\mathrm{b}_{3} \Delta \mathrm{BW}+\text { Herd-Trial }_{\mathrm{j}}+ \\
& \mathrm{CA}_{\mathrm{k}}+\mathrm{YS}_{\mathrm{l}}+\text { Lactwk }_{\mathrm{m}}+\sum_{\mathrm{n}=0}^{2} \mathrm{a}_{\mathrm{np}} \Phi_{\mathrm{n}}+ \\
& \sum_{\mathrm{n}=0}^{2} \mathrm{pe}_{\mathrm{np}} \Phi_{\mathrm{n}}+\mathrm{e}_{\mathrm{jklmp}}
\end{aligned}
$$

and

$$
\begin{aligned}
\text { DMI }_{\mathrm{ijklmp}}= & \mathrm{b}_{1 \mathrm{i}} \mathrm{ECM}+\mathrm{b}_{2 \mathrm{i}} \mathrm{MBW}+\mathrm{b}_{\mathrm{ii}} \Delta \mathrm{BW}+\text { Herd-Trial }_{\mathrm{j}}+ \\
& \mathrm{CA}_{\mathrm{k}}+\mathrm{YS}_{1}+\text { Lactwk }_{\mathrm{m}}+\sum_{\mathrm{n}=0}^{2} \mathrm{a}_{\mathrm{np}} \Phi_{\mathrm{n}}+ \\
& \sum_{\mathrm{n}=0}^{2} \mathrm{pe}_{\mathrm{np}} \Phi_{\mathrm{n}}+\mathrm{e}_{\mathrm{ijklmp}},
\end{aligned}
$$

where $\mathrm{DMI}_{\mathrm{jklmp}}$ and $\mathrm{DMI}_{\mathrm{ijklmp}}$ are the weekly records of DMI in lactation week (Lactwk) $\mathrm{m}$ for cow $\mathrm{p}$ in model [1] and [2], respectively, where cow $\mathrm{p}$ is in calving age (CA) $\mathrm{k}$ in the year-season of calving (YS) $\mathrm{l}$ and from Herd-Trial $\mathrm{j}$. In model [1], $\mathrm{b}_{1}, \mathrm{~b}_{2}$, and $\mathrm{b}_{3}$ are the partial regression coefficients of DMI on ECM, MBW, and $\triangle \mathrm{BW}$ over lactation, respectively. In model [2], $\mathrm{b}_{1 \mathrm{i}}, \mathrm{b}_{2 \mathrm{i}}$, and $b_{3 i}$ are the period-specific partial regression coefficients of DMI on ECM, MBW, and $\triangle \mathrm{BW}$, respectively, in lactation period $\mathrm{i}\left(\mathrm{i}=1\right.$ to 11 ). Herd-Trial $\mathrm{j}_{\mathrm{j}}$ is the fixed effect of herd and trial in which the cows were involved $(\mathrm{j}=1$ to 25$)$, where the cows were from 2 research herds and the trials were herd-specific; $\mathrm{CA}_{\mathrm{k}}$ is the fixed effect of calving age in the month of cows' first calving $(\mathrm{k}=$ 24 to 36$) ; \mathrm{YS}_{1}$ is the fixed effect of year-season of calving, where the year of calving is from 1995 to 2015 and 4 seasons were defined (March to May, June to August, September to November, and December to February; $l=1$ to 64$)$; Lactwk $\mathrm{m}_{\mathrm{m}}$ accounts for the fixed effect of lactation week on DMI $(\mathrm{m}=1$ to 44$) ; \mathrm{a}_{\mathrm{np}}$ and $\mathrm{pe}_{\mathrm{np}}$ are

Table 1. Descriptive statistics of DMI $(\mathrm{kg} / \mathrm{d})$, milk yield $(\mathrm{kg} / \mathrm{d})$, milk composition (\%), and BW $(\mathrm{kg})$ across 44 lactation weeks in 747 primiparous Holstein cows

\begin{tabular}{lcccc}
\hline Item & Mean & SD & Minimum & Maximum \\
\hline DMI $(\mathrm{kg} / \mathrm{d})$ & 19.63 & 2.97 & 5.72 & 40.48 \\
Milk yield $(\mathrm{kg} / \mathrm{d})$ & 28.55 & 6.39 & 2.50 & 47.00 \\
Milk composition (\%) & & & & 4.70 \\
Protein & 3.51 & 0.35 & 2.35 & 6.37 \\
Fat & 4.15 & 0.65 & 2.04 & 5.96 \\
Lactose & 4.96 & 0.26 & 3.97 & 867.1 \\
BW (kg) & 601.0 & 62.2 & 396.5 & \\
\hline
\end{tabular}


the nth regression coefficients of the Legendre polynomial for the random additive genetic effect and for the random permanent environmental effect, respectively, of the cow p; $\Phi_{\mathrm{n}}$ is the term of the second-order Legendre polynomial for $\mathrm{a}_{\mathrm{np}}$ and $\mathrm{pe}_{\mathrm{np}}$, where the time variable is the week of lactation; $\mathrm{e}_{\mathrm{jklmp}}$ and $\mathrm{e}_{\mathrm{ijklmp}}$ are random residuals for model [1] and [2], respectively, which were assumed to be with heterogeneous variances along lactation and were divided into 11 classes of heterogeneous residual variances (every 4 consecutive weeks of the 44 lactation weeks was set as 1 class).

We initially tested the significance of the period-specific partial regressions of DMI on energy sinks (ECM, MBW, and $\triangle \mathrm{BW}$ ) by using PROC MIXED in SAS 9.3 (SAS Institute Inc., Cary, NC), where the periodspecific partial regressions of DMI on energy sinks (ECM, MBW, and $\triangle \mathrm{BW}$ ) were shown to be significant $(P<0.05)$. In this test, we used a mixed model that included the same fixed effects as model [2] and a random cow effect with a third-order Legendre polynomial of lactation weeks, but without using pedigree relationships. Thereafter, we carried out a genetic analysis for RFI with model [1] and [2] with pedigree information, using the restricted maximum likelihood in DMU 5.2 (Madsen and Jensen, 2013). Period-specific partial regression coefficients of DMI on ECM, MBW, and $\triangle \mathrm{BW}$ were estimated with model [2] and compared with the partial regression coefficients estimated from model [1]. Variance components and genetic parameters for RFI across lactation were estimated from both model [1] and [2] and were compared with each other.

\section{RESULTS}

\section{Effects of Energy Sinks on DMI in Different Lactation Periods}

Period-specific partial regressions of DMI on ECM (Figure 1A), on MBW (Figure 1B), and on $\triangle B \mathrm{BW}$ (Figure 1C) from RFI model [2] varied across lactation. From the genetic analysis using model [1], the partial regression coefficient of DMI on ECM over lactation was close to $0.15(\mathrm{~kg}$ of $\mathrm{DMI} / \mathrm{kg}$ of $\mathrm{ECM} ; \mathrm{SE}=0.004$; Figure 1A). When the period-specific effect of ECM on DMI was considered in model [2], the effect of ECM on DMI changed significantly across lactation (Figure 1A). In early lactation (periods 1-2), the estimated regression coefficients of DMI on ECM were significantly lower than 0.15 ( $\mathrm{kg}$ of DMI $/ \mathrm{kg}$ of ECM). From period 4 until the end of lactation, partial regression coefficients of DMI on ECM were significantly higher than $0.15(\mathrm{~kg}$ of DMI $/ \mathrm{kg}$ of ECM). The estimated amount of feed intake for $1 \mathrm{~kg}$ of ECM increased from the beginning of lactation until period 4 (Figure $1 \mathrm{~A})$.
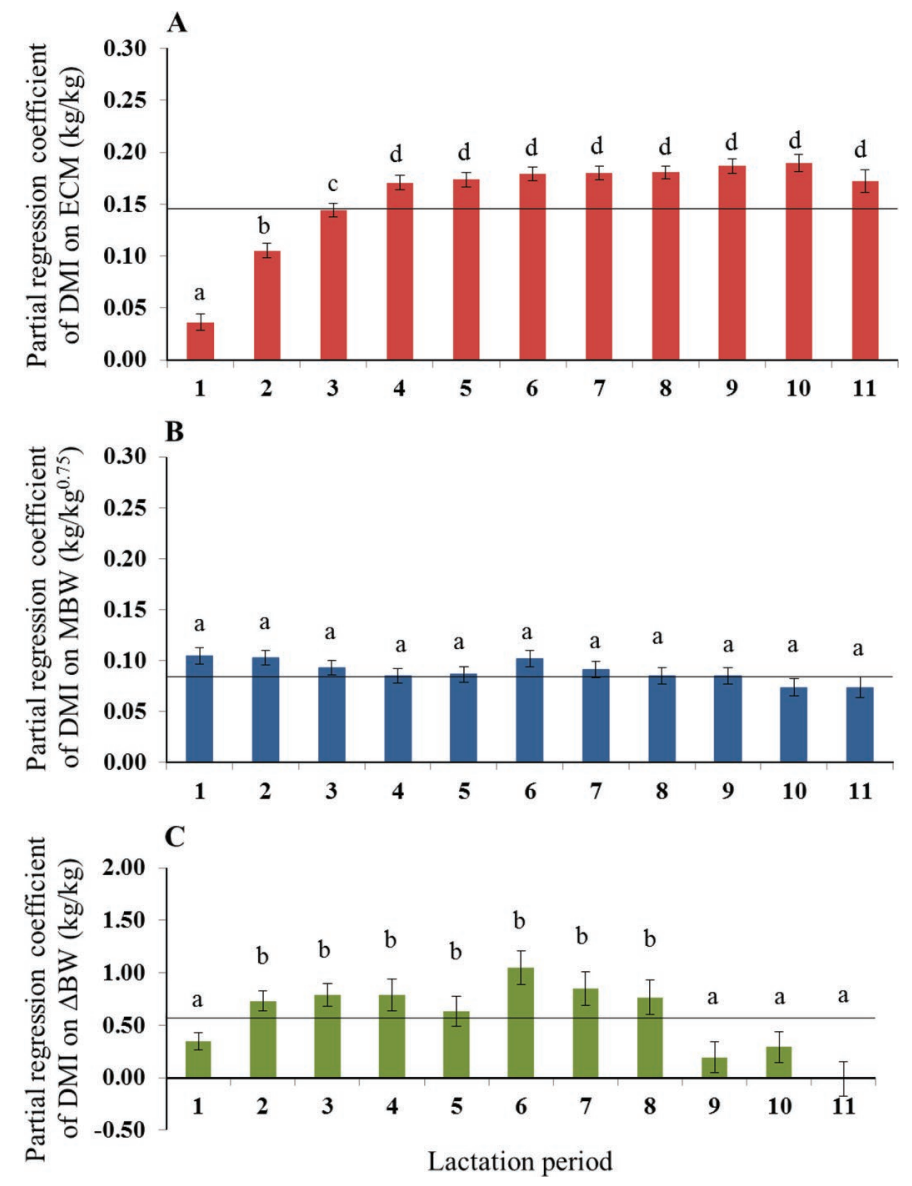

Figure 1. Partial regression coefficients of DMI on (A) ECM, (B) metabolic BW $(\mathrm{MBW})$, and $(\mathrm{C})$ change in $\mathrm{BW}(\Delta \mathrm{BW})$ in each lactation period estimated from residual feed intake (RFI) in model [2]. Error bars are standard errors. Bars not sharing the same letter (a-d) are significantly different $(P<0.05)$. Horizontal lines are the partial regression coefficients of DMI on ECM, MBW, and $\triangle \mathrm{BW}$ across 44 lactation weeks estimated from model [1], respectively. Color version available online.

When model [1] was used, the estimated partial regression coefficient of DMI on MBW over lactation was around 0.08 ( $\mathrm{kg}$ of $\mathrm{DMI} / \mathrm{kg}$ of $\mathrm{MBW} ; \mathrm{SE}=0.005$; Figure 1B). In model [2], the estimated partial regression coefficients of DMI on MBW tended to be greater than $0.08(\mathrm{~kg}$ of $\mathrm{DMI} / \mathrm{kg}$ of MBW) in period 1,2 , and 6 , but were generally stable across periods (Figure 1B). When model [1] was used, the partial regression coefficient of DMI on $\triangle \mathrm{BW}$ over lactation was $0.57(\mathrm{~kg}$ of $\mathrm{DMI} / \mathrm{kg}$ of $\Delta \mathrm{BW} ; \mathrm{SE}=0.06$; Figure $1 \mathrm{C}$ ). In model [2], partial regression coefficients of DMI on $\Delta \mathrm{BW}$ were significantly lower than $0.57(\mathrm{~kg}$ of $\mathrm{DMI} / \mathrm{kg}$ of $\Delta \mathrm{BW})$ at the beginning of lactation (period 1) and in the end of lactation (periods 9-11), and tended to be higher than $0.57(\mathrm{~kg}$ of $\mathrm{DMI} / \mathrm{kg}$ of $\Delta \mathrm{BW}$ ) from periods 2 to 8 (Figure 1C). 


\section{Genetic Parameters for RFI Estimated from 2 Models}

Variance Components and Heritability. Variance components estimated from both RFI models generally followed similar patterns (Figure 2). In RFI model [2], where the partial regression coefficients of DMI on energy sinks were allowed to change over lactation, lower and more stable genetic variances for RFI along lactation were observed compared with the genetic variances estimated from model [1]. The permanent environmental variances estimated from both models were similar. The residual variance from model [2] was slightly lower than model [1] across the whole lactation periods. The total variance from RFI model [2] was lower than the total variance from model [1] in most of the lactation. Additionally, in most of the lactation weeks, the correlations between observed DMI and predicted DMI were higher in model [2] than in model [1], especially in the first 3 lactation weeks when the correlations between predicted and observed DMI were on average $2 \%$ higher in model [2] than in model [1].

The heritability for RFI estimated from both models followed a similar trajectory, decreasing from the beginning of lactation to lactation wk 10 from around 0.2 to 0.1 before an increase until around lactation wk 30 (Figure 3). The heritability for RFI estimated from model [1] ranged from 0.10 to 0.29 across lactation (mean $\mathrm{SE}=0.05$ ), whereas the heritability from model [2] was slightly lower and more stable over lactation, ranging from 0.10 to 0.23 across lactation (mean $\mathrm{SE}=$ 0.05; Figure 3).

Genetic Correlations for RFI Across Lactation. Residual feed intake in middle and late lactation were genetically highly correlated, whereas RFI in early lactation was negatively correlated with RFI in later lactation weeks (Figure 4). Genetic correlations for RFI across 44 lactation weeks estimated from model [1] and model [2] ranged from -0.51 to 1 and from -0.29 to 1 , respectively. Genetic correlations for RFI were shown to be negative between early and middle lactation weeks from both models. However, the most extreme negative genetic correlation for RFI between early and middle lactation was reduced to -0.29 in RFI model [2] (Figure 4B), compared with -0.51 from model [1] (Figure 4A).

\section{DISCUSSION}

\section{Lactation Stage Influenced the Effects of Energy Sinks in RFI}

Our results indicated that the allocation of energy (seen as feed intake) to common energy sinks (ECM, $\mathrm{MBW}$, and $\triangle \mathrm{BW}$ ) varied across lactation based on the current definition of RFI. The assumption of constant partial regressions of feed intake on ECM, MBW, and $\triangle \mathrm{BW}$ over lactation was not always sufficient to explain the feed utilization for energy sinks across lactation and tended to result in roughly average information of all period-specific effects. More specifically, the partial regression coefficients of DMI on ECM were significantly different between early and later lactation stages, with the effect of ECM on DMI being much lower in early lactation compared with later lactation; this result could partly reflect the change of metabolic condition in dairy cows during lactation. A cow's MY increases sharply after calving, and feed intake peaks no earlier than lactation wk 10 to 12 (Gravert, 1985; Mäntysaari et al., 2012; Berry et al., 2014). In early lactation, the energy intake from diet cannot meet the energy demand for rapidly increased MY, and part of the required energy comes from the mobilization of body reserves (Berglund and Danell, 1987; Mao et al., 2004; Banos and Coffey, 2010). After early lactation, the feed intake of cows remains at a relatively high level to provide energy for milk production, and body reserves are gradually restored (Mao et al., 2004). The potential change in the relationship between feed intake and milk production could also be reflected by a varying genetic correlation between DMI and MY across lactation from previous studies, especially in early lactation when feed intake and MY were weakly genetically correlated (Veerkamp and Thompson, 1999; Hüttmann et al., 2009; Manzanilla Pech et al., 2014). In addition, it should also be noted that the partial regression coefficients of DMI on ECM were relatively constant from period 3 (approximately from DIM 57) until the end of lactation in our study, indicating a fairly weak influence of lactation stage on partial efficiency of DMI on ECM from period 3 onwards. This result is in agreement with $\mathrm{Lu}$ et al. (2017), who also reported an insignificant influence of lactation stage on the partial regression of feed intake on milk energy when 42-d records between 50 and 200 DIM were included in the analysis.

The utilization of feed intake for $\Delta \mathrm{BW}$ was significantly influenced by the lactation period in our study. Generally, lactating cows lose BW at the beginning of lactation and gradually gain BW in later lactation (Vallimont et al., 2010). The catabolism and anabolism of body tissues correspond to different energy values, such that the energy generated from a 1-kg loss in BW is less than the energy required for a 1-kg gain (O'Mara, 2000; Coleman et al., 2010). Therefore, the effect of $\Delta \mathrm{BW}$ on feed intake in early lactation (mostly BW loss) would be expected to differ from the effect in middle and late lactation (mostly BW gain). The feed intake of cows could hardly follow a constant partial regression of the cows' $\Delta \mathrm{BW}$ over the whole lactation. In our study, we 
defined a period-specific partial regression of DMI on $\triangle \mathrm{BW}$, where $\mathrm{BW}$ loss was mainly in lactation period 1 and, to some extent, in period 2; after period 2, we mainly observed BW gain. As an alternative, a few studies used partial regressions of DMI on both BW loss and BW gain to explain the associations of feed intake with BW change for estimation of RFI (Coleman et al., 2010; Mäntysaari et al., 2012). We did not specify BW loss and BW gain in the current study because the period-specific partial regressions of DMI
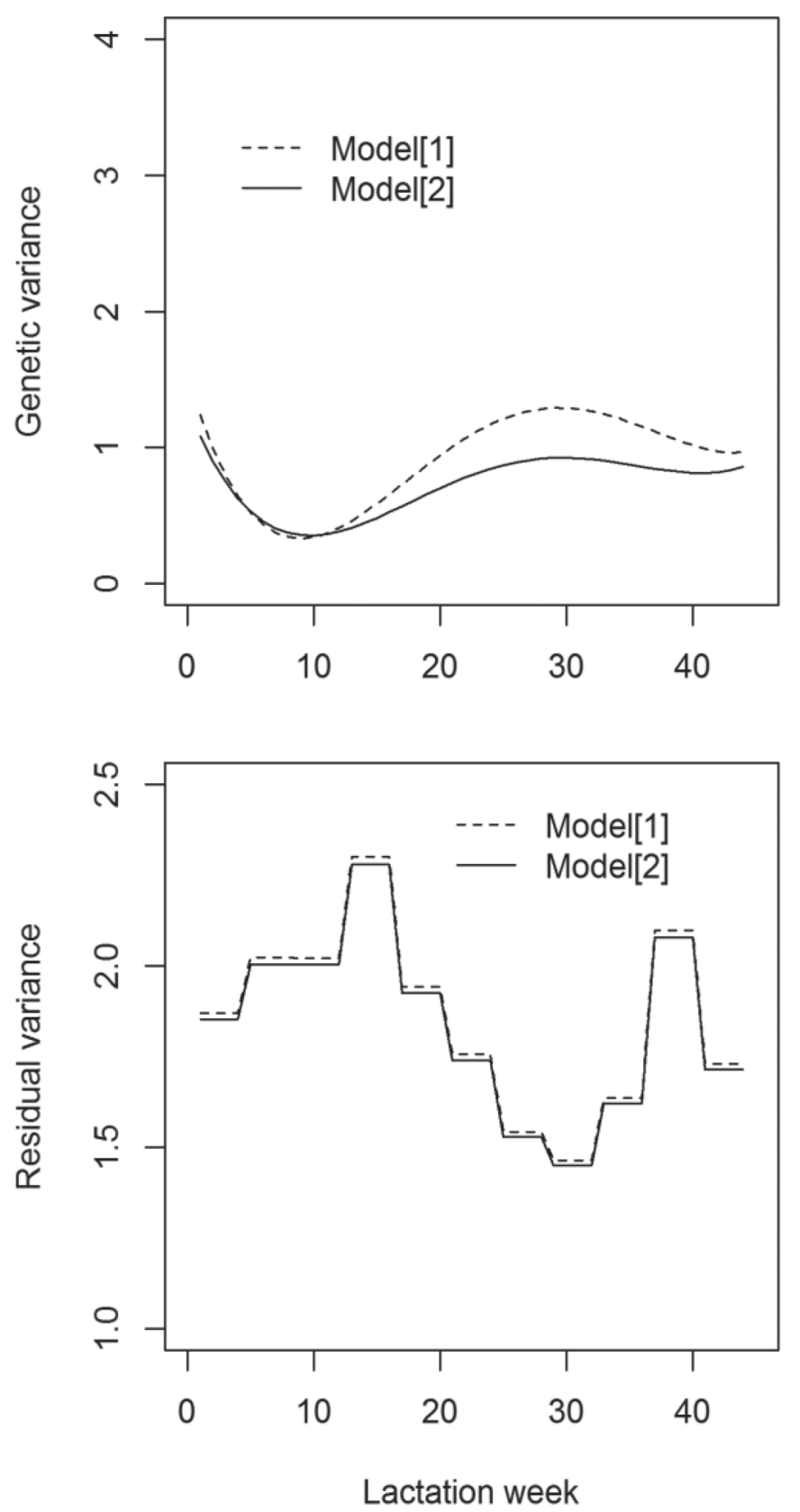

on $\Delta \mathrm{BW}$ were considered and very few cows had BW loss after period 2 .

The efficiency of cows would be assessed differently depending on whether lactation stage is considered in calculating RFI, especially for cows' efficiency in early lactation. For example, considering 2 cows from our data set in lactation wk 3; cow 1 had a higher ECM yield and higher feed intake than cow 2 in lactation wk 3 , whereas cow 2 was much heavier and mobilized more BW than cow 1. The RFI for both cows in this week
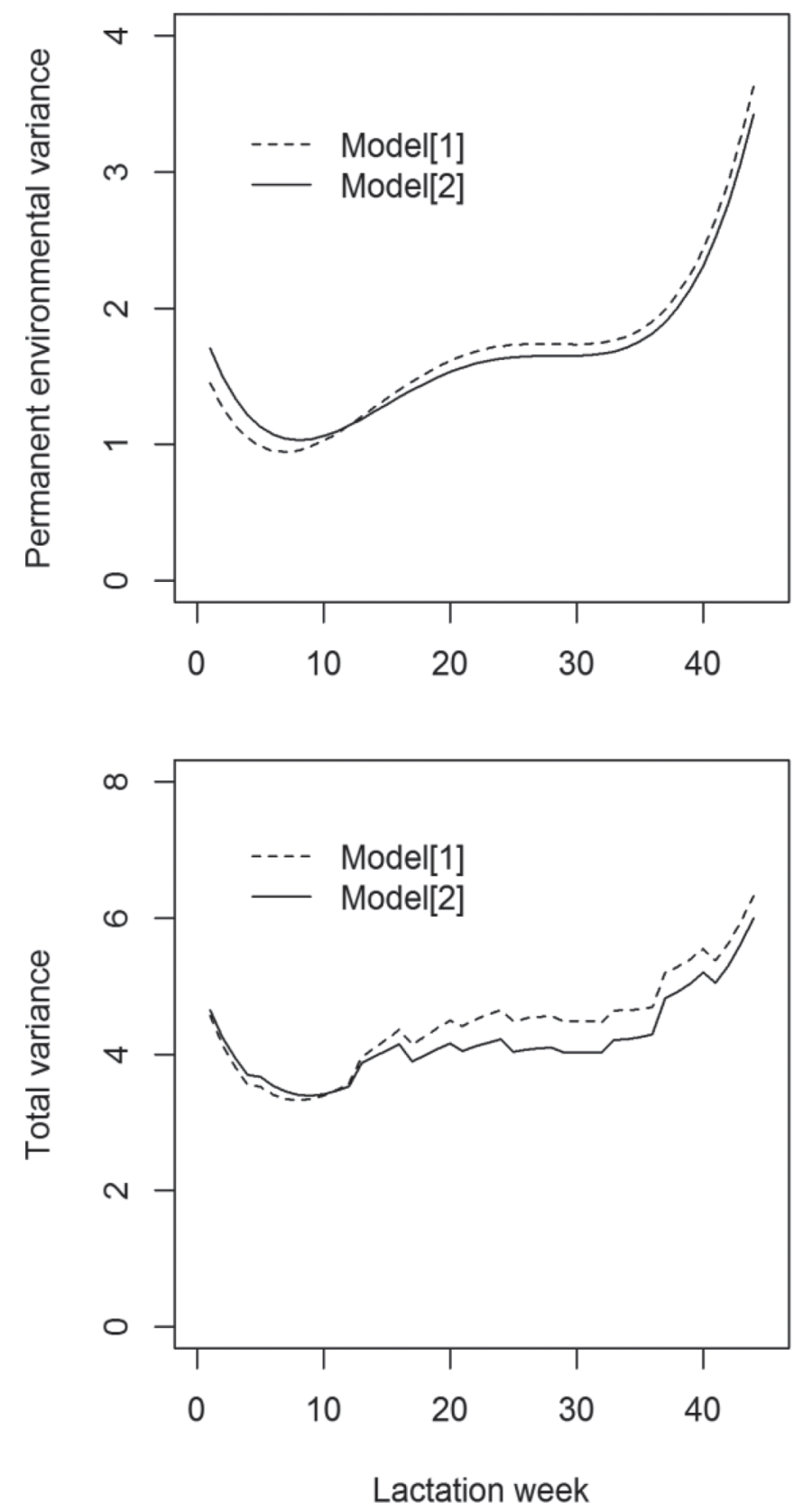

Figure 2. Genetic variances, permanent environmental variances, residual variances, and total variances for residual feed intake (RFI) across 44 lactation weeks estimated from RFI in model [1] (dashed lines) and RFI in model [2] (solid lines). 


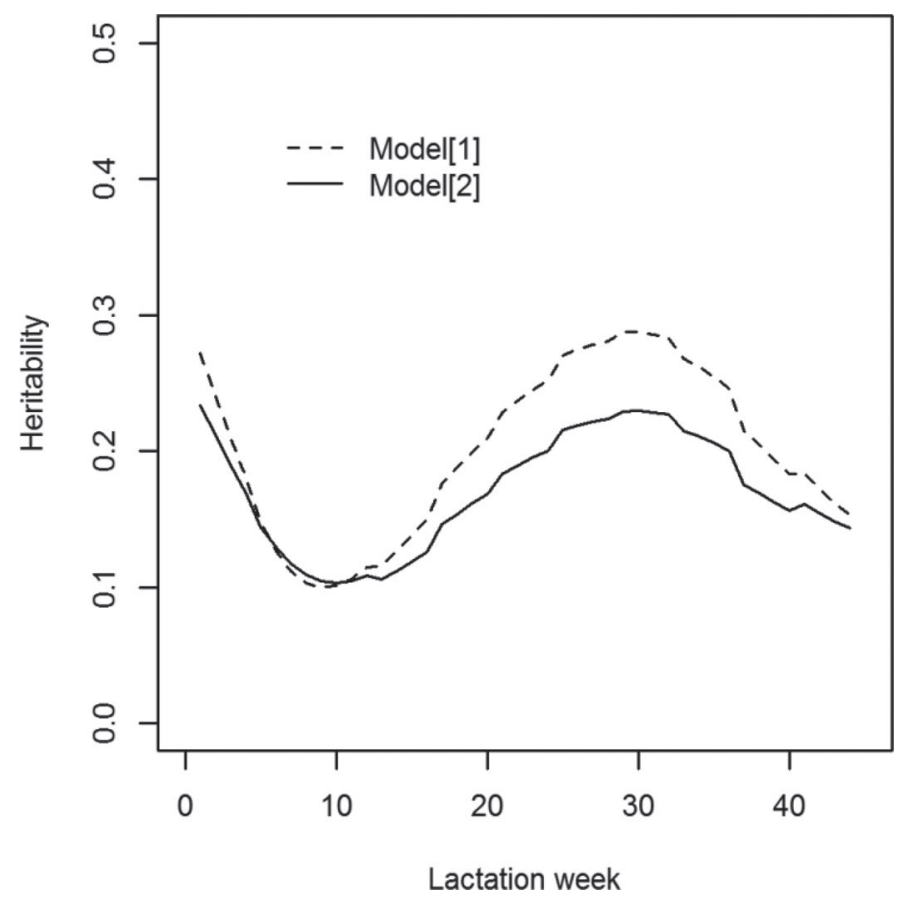

Figure 3. Heritability for residual feed intake (RFI) across 44 lactation weeks estimated from RFI in model [1] (dashed line) and RFI in model [2] (solid line).

were estimated as the residuals of DMI after adjusting for ECM yield, MBW, and $\triangle \mathrm{BW}$. When model [1] was used to estimate RFI, cow 1 and 2 were very similar in RFI; however, when model [2] was used, cow 2 had a lower RFI and was more efficient than cow 1. Cow 2 met energy requirements in part by mobilizing body reserves, whereas cow 1 met energy requirements solely by intake of feed. The difference was reflected in RFI from model [1] and [2] due to the different partial regression coefficients of DMI on energy sinks for early lactation.

\section{Genetic Parameters for RFI Across Lactation}

The genetic variance for RFI varied along lactation, consistent with the findings of Tempelman et al. (2015), who reported unequal genetic variances for RFI from DIM 50 to 200. In our study, genetic variances for RFI estimated from model [1] and [2] were slightly different. After accounting for the period-specific effects of energy sinks, the genetic variance for RFI was lower and more stable over lactation in model [2] than in model [1]. The higher genetic variance for RFI estimated from model [1] might partly come from the unexplained variance in the period-specific effects of energy sinks. The heritability for RFI estimated from model [2] was slightly lower than model [1] and more stable over the lactation, mainly due to the more stable genetic variance estimated from model [2] compared with model [1] over lactation. The heritability of RFI in dairy cattle ranged from 0.10 to 0.23 across lactation in our study, consistent with the heritability reported by Tempelman et al. (2015; i.e., 0.10-0.25 for DIM 50-200).
A

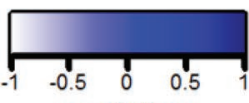

correlations

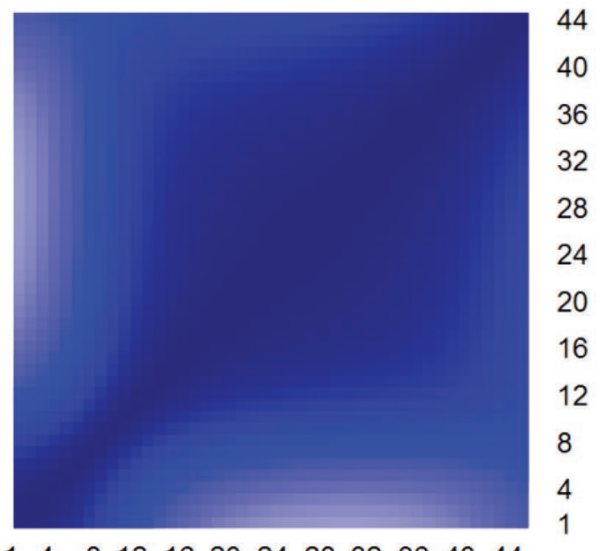

$\begin{array}{llllllllllll}1 & 4 & 8 & 12 & 16 & 20 & 24 & 28 & 32 & 36 & 40 & 44\end{array}$

44
40
36
32
28
24
20
16
12
8
4
1

Lactation week
B

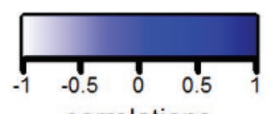

correlations
44

40

36

32

28

24

20

16

12

8

4
1

$\begin{array}{llllllllllll}1 & 4 & 8 & 12 & 16 & 20 & 24 & 28 & 32 & 36 & 40 & 44\end{array}$

Figure 4. Genetic correlations for residual feed intake (RFI) across 44 lactation weeks estimated from (A) RFI model [1] and (B) RFI model [2]. Color version available online. 
We found that RFI was genetically different across lactation. Liinamo et al. (2015) reported a similar finding of the genetic heterogeneity of residual energy intake during $30 \mathrm{wk}$ of lactation in Nordic Red dairy cattle. The extreme negative genetic correlations between early and middle lactation estimated from model [1] tended to be mitigated when period-specific partial regressions of DMI on energy sinks were included in model [2]. However, this type of correction for the period-specific effects of energy sinks seemed not to influence the conclusion of a genetic heterogeneity of RFI across lactation. In other words, the heterogeneity of RFI across lactation could stem from the basic definition of RFI. Basically, RFI is defined based on the phenotypes of DMI, MY, and BW. Milk yield and DMI have been reported as genetically different traits over lactation, especially between early and later lactation stages (Veerkamp and Thompson, 1999; Manzanilla Pech et al., 2014; Li et al., 2016). Body weight tended to be a more consistent trait across lactation, but the genetic correlation of $\mathrm{BW}$ between early and later lactation was still not unity (Veerkamp and Thompson, 1999; Manzanilla Pech et al., 2014). Properties of component traits of RFI (DMI, MY, and BW) across lactation could influence the genetic properties of RFI across lactation.

\section{Challenges of Using RFI for FE in Dairy Cattle}

The challenges of using RFI as a measure of FE in dairy cattle have been widely discussed (e.g., Kennedy et al., 1993; Berry and Crowley, 2013; Tempelman et al., 2015). Selecting for RFI has the risk of being mathematically equivalent to selecting for negative energy balance if $\triangle \mathrm{BW}$ is not accounted for properly (Veerkamp, 2002). Another issue is that RFI is genetically correlated with its component energy sink traits (e.g., MY, BW, and $\triangle \mathrm{BW}$ ), as RFI was only phenotypically adjusted for the component traits; therefore, selection on RFI would generate correlated responses in production and in BW (Kennedy et al., 1993; Veerkamp and Emmans, 1995). Considering the challenges of using RFI for FE in dairy cattle, we stressed the influence of lactation stages in defining RFI and the potential heterogeneity of RFI across lactation. We focused on the influence of lactation stage on the allocation of DMI to energy sinks when data for modeling RFI cover the entire lactation. Constant partial regressions of DMI on energy sinks were found to be insufficient to account for the effects of energy sinks across lactation, especially during early lactation. Our modeling strategy for RFI in the current study helped us to understand the influence of lactation stages on RFI and could provide useful information for a better modeling of RFI or FE traits in the future. One limitation of the present study was that we defined RFI based on the phenotypic adjustment of energy sinks for DMI, so that RFI would not be genetically independent from energy sink traits. In contrast, the concept of multiple trait selection or modeling of feed intake itself and the energy sink traits could be alternatives of the current RFI (Kennedy et al., 1993; Veerkamp and Emmans, 1995; Lu et al., 2015). However, as FE-related traits (e.g., DMI, MY, BW) in a multiple-trait selection can be genetically different across lactation, the influence of lactation stage on FE-related traits should be considered in a multiple trait selection for FE in dairy cattle.

\section{CONCLUSIONS}

When defining RFI in lactating dairy cows, we found that the partial regression coefficients of cows' feed intake on ECM, MBW, and $\triangle \mathrm{BW}$ varied across lactation, especially in early lactation. Constant partial regressions of feed intake on energy sinks were not always sufficient to explain the effects of ECM, MBW, and $\triangle \mathrm{BW}$ across lactation in defining RFI. Heritability for RFI ranged from 0.10 to 0.23 across lactation; RFI was genetically different across lactation, especially between early and later lactation stages. Considering period-specific partial regressions of DMI on ECM, $\mathrm{MBW}$, and $\triangle \mathrm{BW}$ in RFI could affect the assessment of RFI and the estimated genetic parameters for RFI across lactation.

\section{ACKNOWLEDGMENTS}

This study was part of the joint project "Feed Utilization in Nordic Cattle (FUNC)" among Nordic countries (Denmark, Finland, Norway, and Sweden). The authors acknowledge the Danish Cattle Research Center (Foulum, Denmark), Natural Resources Institute Finland (Jokioinen, Finland), and Swedish University of Agricultural Sciences (Uppsala, Sweden) for collaborating in joining data. The authors also acknowledge the Swedish Farmers' Foundation for Agricultural Research (Stockholm, Sweden) for its financial support. The first author is enrolled in the Erasmus Mundus European Graduate School in Animal Breeding and Genetics (EGS-ABG; http://www.egsabg.eu/).

\section{REFERENCES}

Banos, G., and M. P. Coffey. 2010. Genetic association between body energy measured throughout lactation and fertility in dairy cattle. Animal 4:189-199.

Berglund, B., and B. Danell. 1987. Live weight changes, feed consumption, milk yield and energy balance in dairy cattle during the first period of lactation. Acta Agric. Scand. 37:495-509. 
Berry, D. P., M. P. Coffey, J. E. Pryce, Y. de Haas, P. Løvendahl, N. Krattenmacher, J. J. Crowley, Z. Wang, D. Spurlock, K. Weigel, K. Macdonald, and R. F. Veerkamp. 2014. International genetic evaluations for feed intake in dairy cattle through the collation of data from multiple sources. J. Dairy Sci. 97:3894-3905.

Berry, D. P., and J. J. Crowley. 2013. Cell Biology Symposium: Genetics of feed efficiency in dairy and beef cattle. J. Anim. Sci. 91:1594-1613. https://doi.org/10.2527/jas.2012-5862.

Coleman, J., D. P. Berry, K. M. Pierce, A. Brennan, and B. Horan. 2010. Dry matter intake and feed efficiency profiles of 3 genotypes of Holstein-Friesian within pasture-based systems of milk production. J. Dairy Sci. 93:4318-4331.

Gravert, H. O. 1985. Genetic factors controlling feed efficiency in dairy cows. Livest. Prod. Sci. 13:87-99.

Hardie, L. C., L. E. Armentano, R. D. Shaver, M. J. VandeHaar, D. M. Spurlock, C. Yao, S. J. Bertics, F. E. Contreras-Govea, and K. A. Weigel. 2015. Considerations when combining data from multiple nutrition experiments to estimate genetic parameters for feed efficiency. J. Dairy Sci. 98:2727-2737.

Hüttmann, H., E. Stamer, W. Junge, G. Thaller, and E. Kalm. 2009 Analysis of feed intake and energy balance of high-yielding first lactating Holstein cows with fixed and random regression models. Animal 3:181-188.

ICAR. 2016. International Agreement on Recording Practices (ICAR Recording Guidelines). 2016 ed. International Committee for Animal Recording, Rome, Italy. www.icar.org/index.php/publications -technical-materials/recording-guidelines.

Kennedy, B. W., J. H. J. van der Werf, and T. H. E. Meuwissen. 1993. Genetic and statistical properties of residual feed intake. J. Anim. Sci. 71:3239-3250

Koch, R. M., L. A. Swiger, D. Chambers, and K. E. Gregory. 1963. Efficiency of feed use in beef cattle. J. Anim. Sci. 22:486-494.

Li, B., W. F. Fikse, J. Lassen, M. H. Lidauer, P. Løvendahl, P. Mäntysaari, and B. Berglund. 2016. Genetic parameters for dry matter intake in primiparous Holstein, Nordic Red, and Jersey cows in the first half of lactation. J. Dairy Sci. 99:7232-7239.

Liinamo, A.-E., P. Mantysaari, M. H. Lidauer, and E. A. Mantysaari. 2015. Genetic parameters for residual energy intake and energy conversion efficiency in Nordic Red dairy cattle. Acta Agric. Scand. A Anim. Sci. 65:63-72.

Løvendahl, P., and M. G. G. Chagunda. 2011. Covariance among milking frequency, milk yield, and milk composition from automatically milked cows. J. Dairy Sci. 94:5381-5392.

Løvendahl, P., C. Ridder, and N. C. Friggens. 2010. Limits to prediction of energy balance from milk composition measures at individual cow level. J. Dairy Sci. 93:1998-2006.

Lu, Y., M. J. Vandehaar, D. M. Spurlock, K. A. Weigel, L. E. Armentano, C. R. Staples, E. E. Connor, Z. Wang, N. M. Bello, and R. J. Tempelman. 2015. An alternative approach to modeling genetic merit of feed efficiency in dairy cattle. J. Dairy Sci. 98:6535-6551.

Lu, Y., M. J. Vandehaar, D. M. Spurlock, K. A. Weigel, L. E. Armentano, C. R. Staples, E. E. Connor, Z. Wang, M. Coffey, R. F. Veerkamp, Y. de Haas, and R. J. Tempelman. 2017. Modeling genetic and nongenetic variation of feed efficiency and its partial relationships between component traits as a function of management and environmental factors. J. Dairy Sci. 100:412-427.

Madsen, P., and J. Jensen. 2013. DMU-A Package for Analyzing Multivariate Mixed Models. Version 6, Release 5.2. Quantitative Genetics and Genomics (QGG), Aarhus University, Tjele, Denmark.

Mäntysaari, P., A.-E. Liinamo, and E. A. Mäntysaari. 2012. Energy efficiency and its relationship with milk, body, and intake traits and energy status among primiparous Nordic Red dairy cattle. J. Dairy Sci. 95:3200-3211.

Manzanilla Pech, C. I. V., R. F. Veerkamp, M. P. L. Calus, R. Zom, A. van Knegsel, J. E. Pryce, and Y. De Haas. 2014. Genetic pa- rameters across lactation for feed intake, fat- and protein-corrected milk, and liveweight in first-parity Holstein cattle. J. Dairy Sci. 97:5851-5862.

Manzanilla-Pech, C. I. V., R. F. Veerkamp, R. J. Tempelman, M. L. van Pelt, K. A. Weigel, M. VandeHaar, T. J. Lawlor, D. M. Spurlock, L. E. Armentano, C. R. Staples, M. Hanigan, and Y. De Haas. 2016. Genetic parameters between feed-intake-related traits and conformation in 2 separate dairy populations - The Netherlands and United States. J. Dairy Sci. 99:443-457.

Mao, I. L., K. Sloniewski, P. Madsen, and J. Jensen. 2004. Changes in body condition score and in its genetic variation during lactation. Livest. Prod. Sci. 89:55-65.

McDonald, P., R. A. Edwards, J. F. D. Greenhalgh, C. A. Morgan, L. A. Sinclair, and R. G. Wilkinson. 2011. Animal Nutrition. 7th ed. Pearson Education Limited, London, UK.

Nielsen, H. M., N. C. Friggens, P. Løvendahl, J. Jensen, and K. L. Ingvartsen. 2003. Influence of breed, parity, and stage of lactation on lactational performance and relationship between body fatness and live weight. Livest. Prod. Sci. 79:119-133.

O'Mara, F. 2000. A Net Energy System for Cattle and Sheep, Version 1.2. Univ. Coll. Dublin, Ireland.

Patience, J. F., M. C. Rossoni-Serão, and N. A. Gutiérrez. 2015. A review of feed efficiency in swine: Biology and application. J. Anim. Sci. Biotechnol. 6:33.

Roche, J. R., N. C. Friggens, J. K. Kay, M. W. Fisher, K. J. Stafford, and D. P. Berry. 2009. Invited review: Body condition score and its association with dairy cow productivity, health, and welfare. J. Dairy Sci. 92:5769-5801.

Sjaunja, L. O., L. Baevre, L. Junkkarinen, J. Pedersen, and J. Setälä. 1990. A Nordic proposal for an energy corrected milk (ECM) formula. Pages 156-157 in Proceedings of the 27th Biennial Session of the International Committee for Animal Recording (ICAR), Paris, France. EAAP Publication No. 50, Centre for Agricultural Publishing and Documentation (Pudoc), Wageningen, the Netherlands.

Tempelman, R. J., D. M. Spurlock, M. Coffey, R. F. Veerkamp, L. E. Armentano, K. A. Weigel, Y. de Haas, C. R. Staples, E. E. Connor, Y. Lu, and M. J. VandeHaar. 2015. Heterogeneity in genetic and nongenetic variation and energy sink relationships for residual feed intake across research stations and countries. J. Dairy Sci. 98:2013-2026.

Vallimont, J. E., C. D. Dechow, J. M. Daubert, M. W. Dekleva, J. W. Blum, C. M. Barlieb, W. Liu, G. A. Varga, A. J. Heinrichs, and C. R. Baumrucker. 2010. Genetic parameters of feed intake, production, body weight, body condition score, and selected type traits of Holstein cows in commercial tie-stall barns. J. Dairy Sci. 93:4892-4901.

VandeHaar, M. J., L. E. Armentano, K. Weigel, D. M. Spurlock, R. J. Tempelman, and R. Veerkamp. 2016. Harnessing the genetics of the modern dairy cow to continue improvements in feed efficiency. J. Dairy Sci. 99:4941-4954.

Veerkamp, R. F. 2002. Feed intake and energy balance in lactating animals. Session 10-01 in Proc. 7th World Congr. Genet. Appl. Livest. Prod., Montpellier, France.

Veerkamp, R. F., and G. C. Emmans. 1995. Sources of genetic variation in energetic efficiency of dairy cows. Livest. Prod. Sci. 44:8797.

Veerkamp, R. F., and R. Thompson. 1999. A covariance function for feed intake, live weight, and milk yield estimated using a random regression model. J. Dairy Sci. 82:1565-1573.

Wolc, A., J. Arango, T. Jankowski, P. Settar, J. E. Fulton, N. P. O Sullivan, R. Fernando, D. J. Garrick, and J. C. M. Dekkers. 2013 Pedigree and genomic analyses of feed consumption and residua feed intake in laying hens. Poult. Sci. 92:2270-2275. 